\title{
Research on the $\mathrm{SF}_{6}$ decomposition components of the GIS bus spike $P D$ and the insulator surface PD
}

\author{
Du SHEN1, a, Jiangjiang QU2, b \\ ${ }^{1}$ North China Electric Power University, Changping District, Beijing 102206, China \\ ${ }^{2}$ North China Electric Power University, Changping District, Beijing 102206, China \\ aemail: 601790175@qq.com, bemail:920052373@qq.com
}

Keywords: $\mathrm{SF}_{6}$; bus spike; partial discharge; ratio of components

\begin{abstract}
According to the problem that the intelligence is not high of the recognition of GIS PD types by $\mathrm{SF}_{6}$ decomposition components, using the real $110 \mathrm{kV}$ GIS platform, simulating two kinds of insulation defects $\mathrm{PD}$ of $\mathrm{SF}_{6}$ gas, and making the research on the change of the four kinds of gases of $\mathrm{CO}_{2}, \mathrm{CF}_{4}, \mathrm{SO}_{2} \mathrm{~F}_{2}$, and $\mathrm{SOF}_{2}$, then making the research on the ratio of components of $\mathrm{c}\left(\mathrm{SOF}_{2}\right) / \mathrm{c}\left(\mathrm{SO}_{2} \mathrm{~F}_{2}\right)$, and $\mathrm{c}\left(\mathrm{CF}_{4}+\mathrm{CO}_{2}\right) / \mathrm{c}\left(\mathrm{SOF}_{2}+\mathrm{SO}_{2} \mathrm{~F}_{2}\right)$. The results show that the two types of ratio of components of the GIS bus spike PD and the insulator surface PD are significantly different. Therefore, the two types of ratio of components can as the features to identify the GIS bus spike PD and the insulator surface PD.
\end{abstract}

\section{Introduction}

$\mathrm{SF}_{6}$ gas is widely used in gas insulated switchgear (GIS) as an excellent insulating medium. Under normal circumstances, the chemical property of $\mathrm{SF}_{6}$ is very stable, and not easy to break down. But in the case of the GIS device has internal insulation defects and partial discharge, $\mathrm{SF}_{6}$ gas will break down and produce a trace of the gas. [1].

High energy electron impact caused by high electric field in the partial discharge will cause $\mathrm{SF}_{6}$ gas decomposition.

$$
\begin{aligned}
& e+S F_{6} \rightarrow S F_{X}+(6-X) F, X=1 \sim 5 \\
& e+S F_{X} \rightarrow S F_{X-1}+F
\end{aligned}
$$

Most primary decomposition products $\mathrm{SF}_{\mathrm{X}}(\mathrm{X}=1,2, \ldots 5)$ will compound to SF6 molecules, but there is water, oxygen and other impurities in the electric chamber. The water, oxygen and other impurities will be associated with the $\mathrm{SF}_{\mathrm{X}}\left(\mathrm{X}=1,2, \ldots\right.$ 5) to generate $\mathrm{CF}_{4}, \mathrm{SO}_{2} \mathrm{~F}_{2}, \mathrm{SOF}_{2}, \mathrm{SO}_{2}, \mathrm{SOF}_{4}$ and other products [2].

If the discharge area is surrounded by carbon material (such as stainless steel metal electrodes, solid insulating materials, etc.), the $\mathrm{F}$ and $\mathrm{O}$ atom in the gas chamber will react with $\mathrm{C}$ atom, producing $\mathrm{CF}_{4}$ and $\mathrm{CO}_{2}$ and other products. At high temperature, the $\mathrm{C}$ atom also reacts with $\mathrm{CO}_{2}$ to generate $\mathrm{CO}[3]$.

In this paper, using the real $110 \mathrm{kV}$ GIS platform, two kinds of insulation defects GIS of bus spike PD and the insulator surface PD will be tested.

This paper will focus on four kinds of gases of $\mathrm{CO}_{2}, \mathrm{CF}_{4}, \mathrm{SO}_{2} \mathrm{~F}_{2}$ and $\mathrm{SOF}_{2}$, and the ratio of components of $\mathrm{c}\left(\mathrm{SOF}_{2}\right) / \mathrm{c}\left(\mathrm{SO}_{2} \mathrm{~F}_{2}\right)$ and $\mathrm{c}\left(\mathrm{CF}_{4}+\mathrm{CO}_{2}\right) / \mathrm{c}\left(\mathrm{SOF}_{2}+\mathrm{SO}_{2} \mathrm{~F}_{2}\right)$. Finally find out the methods to identify the GIS bus spike PD and the insulator surface PD. 


\section{Overview of experimental system}

The whole experimental system is composed of the GIS experimental model, the pressure device, the $\mathrm{SF}_{6}$ component analysis device and the PD monitoring device. The structure of the GIS experimental model is a three phase, and the insulation level is $110 \mathrm{kV}$ which is divided into 6 gas chambers. The gas chamber is separated by a basin insulator, and each gas chamber is provided with the air outlet and the barometer. The gas chamber which is horizontally placed is $1 \#$ and the gas chamber which is vertically placed is 2\#. Gas chromatograph of Huaai GC9760B will be used to analysis $\mathrm{SF}_{6}$ components.

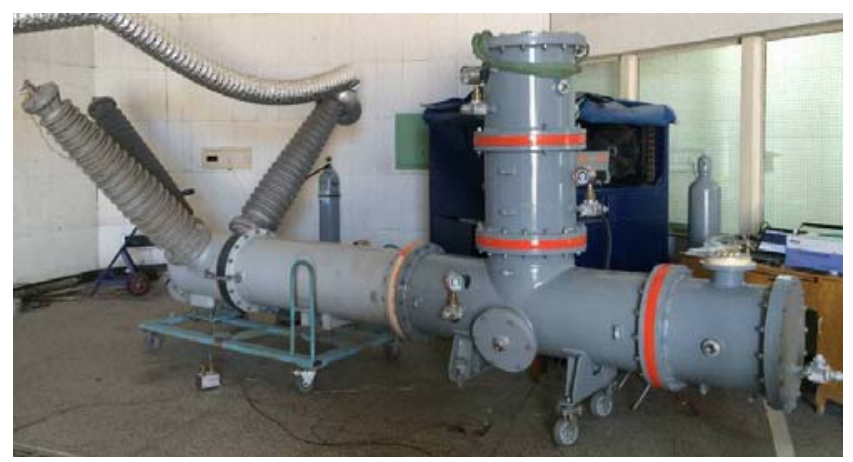

Fig.1.GIS experimental model

\section{Construction of insulation defect}

In the $2 \#$ gas chamber, the electric wire is arranged on the edge of the surface of the insulator. Wire ground clearance is $60 \mathrm{~mm}$, and the surface distance is $63 \mathrm{~mm}$. The bus spike partial discharge model is set up in the 1 \# chamber. Spike length is $4.7 \mathrm{~cm}$, and the gap length is $2.4 \mathrm{~cm}$.

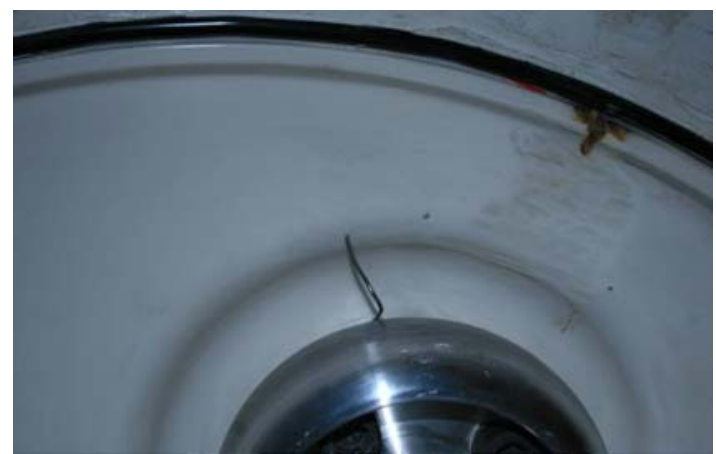

(a) 2\# gas chamber

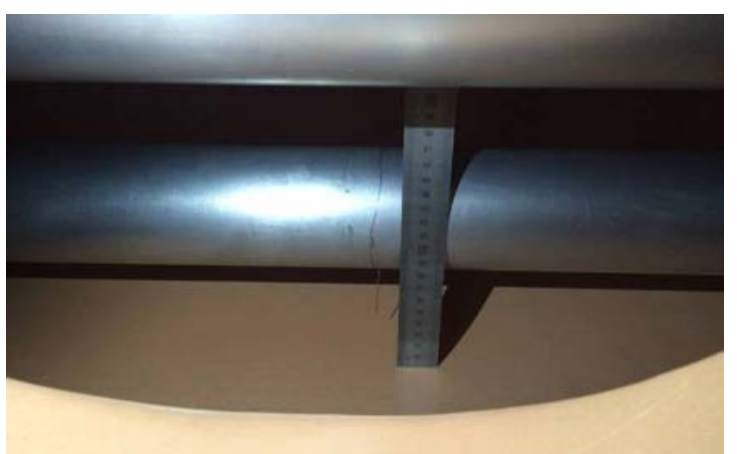

(b) 1\# gas chamber

Fig.2. The construction of insulation defect

\section{Experimental data acquisition and data processing}

In this experiment, high purity $\mathrm{SF}_{6}$ gas $(99.999 \%)$ was used. In this paper, the $\mathrm{SF}_{6}$ gas was measured after filling in the electric chamber. The results show that the content of $\mathrm{CO}_{2}$ in $2 \#$ was $1.5895 \mathrm{ppm}$, the content of $\mathrm{CO}_{2}$ in $2 \#$ was $1.5771 \mathrm{ppm}$, the content of $\mathrm{CF}_{4}$ in $1 \#$ was $1.4895 \mathrm{ppm}$, the content of $\mathrm{CF}_{4}$ in 1 \# was $1.4762 \mathrm{ppm}$.

In order to compare the trend of $\mathrm{SF}_{6}$ decomposition components of two kinds of insulation defects, a constant volume of PD will be ensured as far as possible by adjusting the voltage.

The experiment used the mode of three phases of the common pressure, and the experimental voltage was maintained between $31 \mathrm{kV} \sim 35 \mathrm{kV}$, and the volume of PD of the gas chamber of $2 \#$ and $1 \#$ was $1300 \mathrm{pC}$ to $800 \mathrm{pC}$. The $\mathrm{SF}_{6}$ gas pressure of two gas chambers was $3.5 \mathrm{MPa}$. The experimental voltage was maintained to $240 \mathrm{~h}$ continuously of insulation defects in $2 \#$ and $1 \#$ gas chambers, and gas chromatography was used to trace the $\mathrm{SF}_{6}$ discharge (every $12 \mathrm{~h} \sim 24 \mathrm{~h}$ ), and the quantitative results were obtained. 
(1) The comparison of the same decomposition components of the two gas chambers

After deducting the initial content of the same composition of the two gas chambers, the change rule is obtained by the curve fitting.

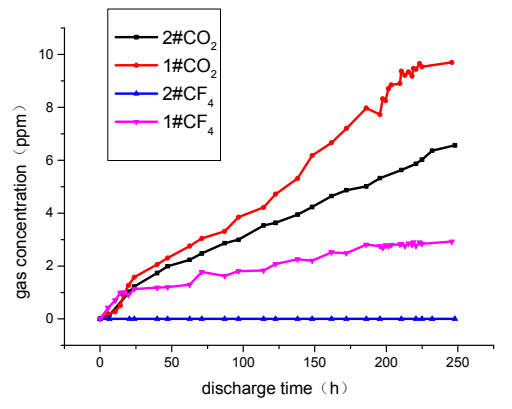

(a) Concentration of $\mathrm{CO}_{2}$ and $\mathrm{CF}_{4}$

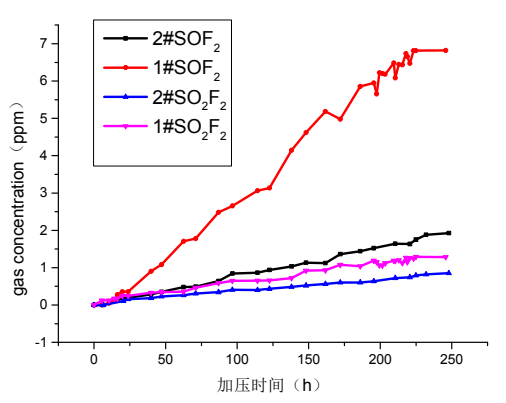

(b) Concentration of $\mathrm{SOF}_{2}$ and $\mathrm{SO}_{2} \mathrm{~F}_{2}$

Fig.3. Comparison of the contents of the two gas chambers

The contents of $\mathrm{CO}_{2}, \mathrm{SOF}_{2}, \mathrm{CF}_{4}$ and $\mathrm{SO}_{2} \mathrm{~F}_{2}$ in the two gas chambers increased with the discharge hours, and the saturation trend was presented. The formation and growth rate of each component of $1 \#$ gas chamber is greater than that of $2 \#$.

In principle, the discharge process of $1 \#$ gas chamber involved epoxy resin solid insulating material, so $\mathrm{CO}_{2}$ and $\mathrm{CF}_{4}$ were produced in larger quantities. $1 \#$ gas chamber only produced a small amount of $\mathrm{C}$ atom in iron spikes, so less $\mathrm{CO}_{2}$ was generated and $\mathrm{CF}_{4}$ almost had no changed. While $\mathrm{SO}_{2} \mathrm{~F}_{2}$ and $\mathrm{SOF}_{2}$ were generated by $\mathrm{SF}_{2}$ and $\mathrm{SF}_{4}$ and $\mathrm{O}$ atoms, the discharge amount of $1 \#$ gas chamber is likely larger than that of $2 \#$ gas chamber.

(2) The relationship between the ratios of the two gas chambers

The value of $\mathrm{c}\left(\mathrm{SOF}_{2}\right) / \mathrm{c}\left(\mathrm{SO}_{2} \mathrm{~F}_{2}\right)$ and $\mathrm{c}\left(\mathrm{CF}_{4}+\mathrm{CO}_{2}\right) / \mathrm{c}\left(\mathrm{SOF}_{2}+\mathrm{SO}_{2} \mathrm{~F}_{2}\right)$ were used to identify the characteristics of two kinds of insulation defects, because these three components were significantly different in size, and these three components had clear physical meaning. The value of $\mathrm{c}\left(\mathrm{SOF}_{2}\right) / \mathrm{c}$ $\left(\mathrm{SO}_{2} \mathrm{~F}_{2}\right)$ can be used to characterize the size of PD energy. The value of $\mathrm{c}\left(\mathrm{CF}_{4}+\mathrm{CO}_{2}\right) / \mathrm{c}$ $\left(\mathrm{SOF}_{2}+\mathrm{SO}_{2} \mathrm{~F}_{2}\right)$ can be used to characterize the deterioration of insulating materials and metal materials.

The ratio of each component was calculated and put together, and then curve fitting was performed, and the change of the ratio of the two gas chambers was obtained.

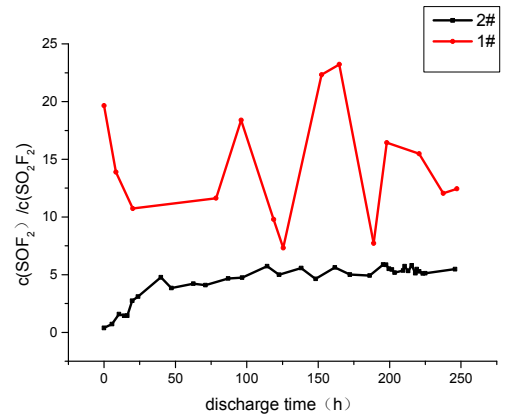

(a) The value of $\mathrm{c}\left(\mathrm{SOF}_{2}\right) / \mathrm{c}\left(\mathrm{SO}_{2} \mathrm{~F}_{2}\right)$

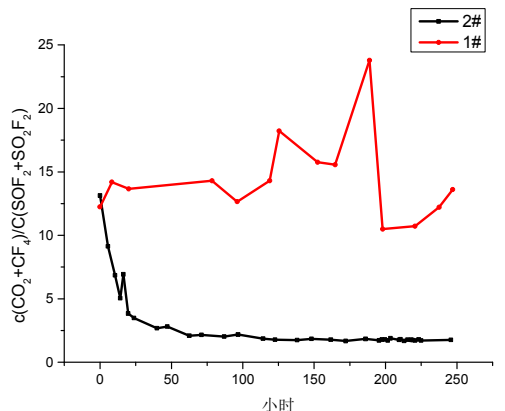

(b) The value of $\mathrm{c}\left(\mathrm{CF}_{4}+\mathrm{CO}_{2}\right) / \mathrm{c}\left(\mathrm{SOF}_{2}+\mathrm{SO}_{2} \mathrm{~F}_{2}\right)$

Fig.4. Comparison of the ratios of the two gas chambers

The value of $\mathrm{c}\left(\mathrm{SOF}_{2}\right) / \mathrm{c}\left(\mathrm{SO}_{2} \mathrm{~F}_{2}\right)$ of two gas chambers were significantly different with the time of discharge. The content of $\mathrm{c}\left(\mathrm{SOF}_{2}\right) / \mathrm{c}\left(\mathrm{SO}_{2} \mathrm{~F}_{2}\right)$ in $1 \#$ is larger than that of $2 \#$.

$\mathrm{SF}_{5}$ and $\mathrm{SF}_{4}$ are low fluoride decomposition of $\mathrm{SF}_{6} . \mathrm{SF}_{5}$ is not stable, and it is easy to restore to $\mathrm{SF}_{6}$ quickly. $\mathrm{SF}_{4}$ has symmetrical structure, and it is stable, and the content of it is large so as the content of $\mathrm{SOF}_{2}$. When the power consumption is low, the amount of $\mathrm{SF}_{4}$ is higher than $\mathrm{SF}_{2}$, so the content of $\mathrm{SOF}_{2}$ in $1 \#$ is higher than that of $\mathrm{SO}_{2} \mathrm{~F}_{2}$, and the value of $\mathrm{c}\left(\mathrm{SOF}_{2}\right) / \mathrm{c}\left(\mathrm{SO}_{2} \mathrm{~F}_{2}\right)$ in $1 \#$ is 
large.

The value of $\mathrm{c}\left(\mathrm{CF}_{4}+\mathrm{CO}_{2}\right) / \mathrm{c}\left(\mathrm{SOF}_{2}+\mathrm{SO}_{2} \mathrm{~F}_{2}\right)$ in the two gas chambers was significantly different with the discharge time. The value of $\mathrm{c}\left(\mathrm{CF}_{4}+\mathrm{CO}_{2}\right) / \mathrm{c}\left(\mathrm{SOF}_{2}+\mathrm{SO}_{2} \mathrm{~F}_{2}\right)$ of $1 \#$ gas chamber was larger than that of $2 \#$ gas chamber.

\section{Conclusion}

The mechanism of the occurrence of $\mathrm{SF}_{6}$ gas by $\mathrm{PD}$ was analyzed, and the decomposition of $\mathrm{SF}_{6}$ gas in the typical insulation defects of the surface of insulator surface along the GIS basin was simulated. When the electrode material was iron and copper, the stable gas decomposition products are $\mathrm{CO}_{2}, \mathrm{CF}_{4}, \mathrm{SO}_{2} \mathrm{~F}_{2}, \mathrm{SOF}_{2}$, and these products increased with the discharge time.

When the kind of insulation defects was bus spike $\mathrm{PD}$, the value of $\mathrm{CO}_{2}, \mathrm{CF}_{4}, \mathrm{SO}_{2} \mathrm{~F}_{2}, \mathrm{SOF}_{2}$ are larger than that of the insulator surface PD. Because the kind of insulation defects of bus spike PD can break out more carbon element, and the power of $\mathrm{PD}$ was also relatively large.

The ratio of components of $\mathrm{c}\left(\mathrm{SOF}_{2}\right) / \mathrm{c}\left(\mathrm{SO}_{2} \mathrm{~F}_{2}\right)$, and $\mathrm{c}\left(\mathrm{CF}_{4}+\mathrm{CO}_{2}\right) / \mathrm{c}\left(\mathrm{SOF}_{2}+\mathrm{SO}_{2} \mathrm{~F}_{2}\right)$ of two kinds of insulation defects $\mathrm{PD}$ had obvious difference. When the kind of insulation defects was bus spike PD, the value of $\mathrm{c}\left(\mathrm{SOF}_{2}\right) / \mathrm{c}\left(\mathrm{SO}_{2} \mathrm{~F}_{2}\right)$ and $\mathrm{c}\left(\mathrm{CF}_{4}+\mathrm{CO}_{2}\right) / \mathrm{c}\left(\mathrm{SOF}_{2}+\mathrm{SO}_{2} \mathrm{~F}_{2}\right)$ were much larger than that of the insulator surface PD.

Therefore, the ratios of components of $\mathrm{c}\left(\mathrm{SOF}_{2}\right) / \mathrm{c}\left(\mathrm{SO}_{2} \mathrm{~F}_{2}\right)$ and $\mathrm{c}\left(\mathrm{CF}_{4}+\mathrm{CO}_{2}\right) / \mathrm{c}\left(\mathrm{SOF}_{2}+\mathrm{SO}_{2} \mathrm{~F}_{2}\right)$ can be used to distinguish the different types of the two insulation defects.

\section{References}

[1] Lv Z, Tek A, Da Silva F, et al. Game on, science-how video game technology may help biologists tackle visualization challenges[J]. PloS one, 2013, 8(3): 57990.

[2] Su T, Wang W, Lv Z, et al. Rapid Delaunay triangulation for randomly distributed point cloud data using adaptive Hilbert curve[J]. Computers \& Graphics, 2016, 54: 65-74.

[3] Lin Y, Yang J, Lv Z, et al. A Self-Assessment Stereo Capture Model Applicable to the Internet of Things[J]. Sensors, 2015, 15(8): 20925-20944.

[4] Yang J, Chen B, Zhou J, et al. A Low-Power and Portable Biomedical Device for Respiratory Monitoring with a Stable Power Source[J]. Sensors, 2015, 15(8): 19618-19632.

[5] Lv Z, Halawani A, Fen S, et al. Touch-less Interactive Augmented Reality Game on Vision Based Wearable Device[J]. Personal and Ubiquitous Computing, 2015, 19(3): 551-567 